\title{
Angiotensin-(1-7) potentiates the coronary vasodilatatory effect of bradykinin in the isolated rat heart
}

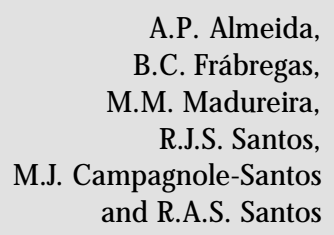

A.P. Almeida,

B.C. Frábregas,

M.M. Madureira,

R.J.S. Santos,

M.J. Campagnole-Santos and R.A.S. Santos

\author{
Departamento de Fisiologia e Biofísica, Instituto de Ciências Biológicas, \\ Universidade Federal de M inas Gerais, Belo Horizonte, MG, Brasil
}

\section{Correspondence \\ R.A.S. Santos \\ Departamento de Fisiologia e \\ Biofísica, ICB, UFM G \\ Av. Antonio Carlos, 6627 \\ 31270-901 Belo Horizonte, MG \\ Brasil \\ Fax: + 55-31-499-2924 \\ E-mail: santos@ icb.ufmg.br}

Presented at the III International Symposium on Vasoactive Peptides, Belo Horizonte, M G, Brasil,

October 8-10, 1999.

Research supported by PRO NEXFINEP, CNPq and FAPEMIG. M.M. Madureira was the recipient of a CNPq fellowship (scientific initiation).

Received February 14, 2000

Accepted March 1, 2000

\begin{abstract}
It has been shown that angiotensin-(1-7) (Ang-(1-7)) infusion potentiates the bradykinin (BK)-induced hypotensive response in conscious rats. The present study was conducted to identify Ang-(1-7)-BK interactions in the isolated rat heart perfused according to the Langendorff technique. Hearts were excised and perfused through the aortic stump under a constant flow with Krebs-Ringer solution and the changes in perfusion pressure and heart contractile force were recorded. Bolus injections of BK $(2.5,5,10$ and $20 \mathrm{ng})$ produced a dosedependent hypotensive effect. Ang-(1-7) added to the perfusion solution $(2 \mathrm{ng} / \mathrm{ml})$ did not change the perfusion pressure or the contractile force but doubled the hypotensive effect of the lower doses of BK. The BK-potentiating Ang-(1-7) activity was blocked by pretreatment with indomethacin $(5 \mathrm{mg} / \mathrm{kg}$, ip) or L-NAME $(30 \mathrm{mg} / \mathrm{kg}$, ip). The Ang-(17) antagonist A-779 (50 ng/ml in Krebs-Ringer) completely blocked the effect of Ang-(1-7) on BK-induced vasodilation. These data suggest that the potentiation of the BK-induced vasodilation by Ang(1-7) can be attributed to the release of nitric oxide and vasodilator prostaglandins through an Ang-(1-7) receptor-mediated mechanism.
\end{abstract}

\section{Introduction}

The renin-angiotensin system plays an important role in the pathogenesis of arterial hypertension, cardiac hypertrophy and chronic heart failure. Since all of its components can be generated or activated at the tissue level, the structural and functional consequences of its activation in organs appear to be due to endocrine as well as paracrine or autocrine mechanisms (1-3).

Inhibitors of angiotensin-converting enzyme (ACE) have been widely used for the treatment of hypertension and other cardiovascular diseases (4-6). The mechanism of action of ACE inhibitors has been thought to be due to interference with circulating or tissue angiotensin II (Ang II) formation and bradykinin (BK) degradation (4-7). However, ACE inhibition also markedly increases 
angiotensin-(1-7) (Ang-(1-7)) concentration in plasma and tissues $(3,8,9)$.

Several reports have described a BKpotentiating activity for Ang-(1-7) (10-15) that could contribute to the cardiovascular effects of $\mathrm{ACE}$ inhibition and $\mathrm{AT}_{1}$ receptor blockers (16). The Ang-(1-7)-BK interaction has been studied in vivo $(10,11)$, in cell culture (12) or in isolated vessels (14). However, there are no data available about the interaction between Ang-(1-7) and BK in the heart. Thus, the present study was conducted to determine the Ang-(1-7) and BK interaction in isolated rat heart perfused by the Langendorff technique.

\section{Material and Methods}

\section{General procedures}

Experiments were performed on male Wistar rats (250-280 g) bred at the Centro de Bioterismo (CEBIO), ICB-UFMG. Ten to fifteen min after an intraperitoneal injection of $200 \mathrm{IU}$ heparin the rats were decapitated. The thorax was opened and the heart was carefully dissected and perfused with KrebsRinger solution through a $1.0 \pm 0.3 \mathrm{~cm}$ aortic stump. The perfusion fluid was maintained at $37 \pm 0.5^{\circ} \mathrm{C}$ with constant flow (WatsonMarlow $501 \mathrm{U}$ pump) and oxygenation (5\% $\mathrm{CO}_{2}$ and $\left.95 \% \mathrm{O}_{2}\right)$. A force transducer $(3 \mathrm{~g}$, model FT03; Grass, West Warwick, RI, USA) was attached through a heart clip to the apex of the ventricles to record the contractile force (tension, g) and perfusion pressure $(\mathrm{mmHg})$ was monitored with a solid-state strain-gauge transducer (Gold, P23XL). All variables were recorded continuously on a computer through a data-acquisition system (Codas, Dataq Instruments, Inc., Akron, OH, USA). Bradykinin was purchased from Sigma (St. Louis, MO, USA) and Ang-(1-7) and A779 were purchased from Bachem (Torrance, CA, USA).

Effect of Ang-(1-7) on the cardiac actions of bradykinin. The hearts were perfused for an initial 20-30-min period with 1) KrebsRinger solution (control, $\mathrm{N}=4$ ) or 2 ) Krebs-Ringer solution containing Ang-(17) $(2.2 \mathrm{nM}, \mathrm{N}=4)$. After the equilibration period, bolus injections of BK $(2.5,5.0$, 10 and $20 \mathrm{ng}$ ) were made at intervals of at least 2-4 min.

Role of cyclo-oxygenase products in the BK-Ang-(1-7) interaction. In order to evaluate the role of cyclo-oxygenase products in the BK-Ang-(1-7) interaction, rats received indomethacin $(5 \mathrm{mg} / \mathrm{kg}$, ip) plus heparin (200 $\mathrm{IU}, i p)$. After $1 \mathrm{~h}$ the rats were decapitated, the thorax was opened and the heart was dissected and perfused with 1) Krebs-Ringer followed by 2) Krebs-Ringer solution containing Ang(1-7) $(2.2 \mathrm{nM}, \mathrm{N}=4)$. The hypotensive effect of bradykinin ( $2.5 \mathrm{ng}$ ) was determined under both perfusion conditions.

Role of NO in the BK-Ang-(1-7) interaction. In order to evaluate the role of nitric oxide (NO) in the BK-Ang-(1-7) interaction, rats received L-NAME $(30 \mathrm{mg} / \mathrm{kg}$, ip) plus heparin (200 IU, ip). After $1 \mathrm{~h}$ the rats were decapitated, the thorax was opened and the heart was dissected and perfused with 1) Krebs-Ringer solution followed by 2) KrebsRinger solution containing Ang-(1-7) (2.2 $\mathrm{nM}, \mathrm{N}=4)$. The hypotensive effect of bradykinin (2.5 ng) was determined under both conditions of perfusion.

Effect of blockade of cyclo-oxygenase and NO-synthase on the BK-Ang-(1-7) interaction. Rats received indomethacin $(5 \mathrm{mg} / \mathrm{kg}$, ip $)$ plus L-NAME $(30 \mathrm{mg} / \mathrm{kg}$, ip $)$ plus heparin (200 IU, ip) and were decapitated $1 \mathrm{~h}$ later, the thorax was opened and the heart was dissected and perfused with 1) KrebsRinger solution followed by 2) KrebsRinger solution containing Ang-(1-7) (2.2 $\mathrm{nM}, \mathrm{N}=4)$. The hypotensive effect of bradykinin $(2.5 \mathrm{ng})$ was determined under both perfusion conditions.

Effect of A-779 on the BK-Ang-(1-7) interaction. The hearts were perfused for an initial 20-30-min period with 1) Krebs-Ringer solution containing the selective Ang-(1-7) 
antagonist (17), A-779, (50 ng/ml, $\mathrm{N}=4)$ followed by 2) Krebs-Ringer solution containing A-779 $(50 \mathrm{ng} / \mathrm{ml})$ plus Ang-(1-7) $(2.2 \mathrm{nM}, \mathrm{N}=4)$. The hypotensive effect of bradykinin (2.5 $\mathrm{ng}$ ) was determined under both perfusion conditions.

\section{Statistical analysis}

Data are reported as means \pm SEM. Statistical analysis was performed by the Student $t$-test or ANOVA followed by the least significant difference test or the NewmanKeuls test, when appropriate. The level of significance was set at $\mathrm{P}<0.05$.

\section{Results}

Ang-(1-7) at $2.2 \mathrm{nM}$ concentration did not change inotropism or pressure perfusion. However, the hypotensive effect produced by bradykinin injected in bolus was potentiated by Ang-(1-7). The magnitude of the potentiation was dependent on the dose of bradykinin, being present only for the lower doses: Ang(1-7) doubled the effect of the lower doses of BK while no significant change in the BK effect was observed when doses of BK higher than 5 ng were used (Figure 1).

To determine whether the effect of Ang(1-7) was due to the release of cyclo-oxygenase products and/or NO release, the effect of the heptapeptide was evaluated in hearts removed from rats pre-treated with indomethacin and/or L-NAME. As shown in Figure 2, the potentiation of the hypotensive effect of BK by Ang-(1-7) was significantly blocked in indomethacin- or L-NAMEtreated rats. Treatment with both drugs produced a similar effect.

The possibility that the BK-potentiating activity of Ang-(1-7) is a receptor-mediated event was evaluated using the selective Ang(1-7) antagonist, A-779. Figure 3 shows that A-779 at $55 \mathrm{nM}$ completely blocked the effect of Ang-(1-7) on the BK-induced vasodilation.

\section{Discussion}

In the present study we have found that: first, Ang-(1-7) potentiates the coronary vasodilatatory effect of $B K$ in the isolated rat hearts; second, the Ang-(1-7)/BK-potentiating activity was blocked by pre-treatment with indomethacin, L-NAME or both drugs. Finally, the Ang-(1-7) antagonist A-779 blocked the effect of Ang-(1-7) on BK-in-
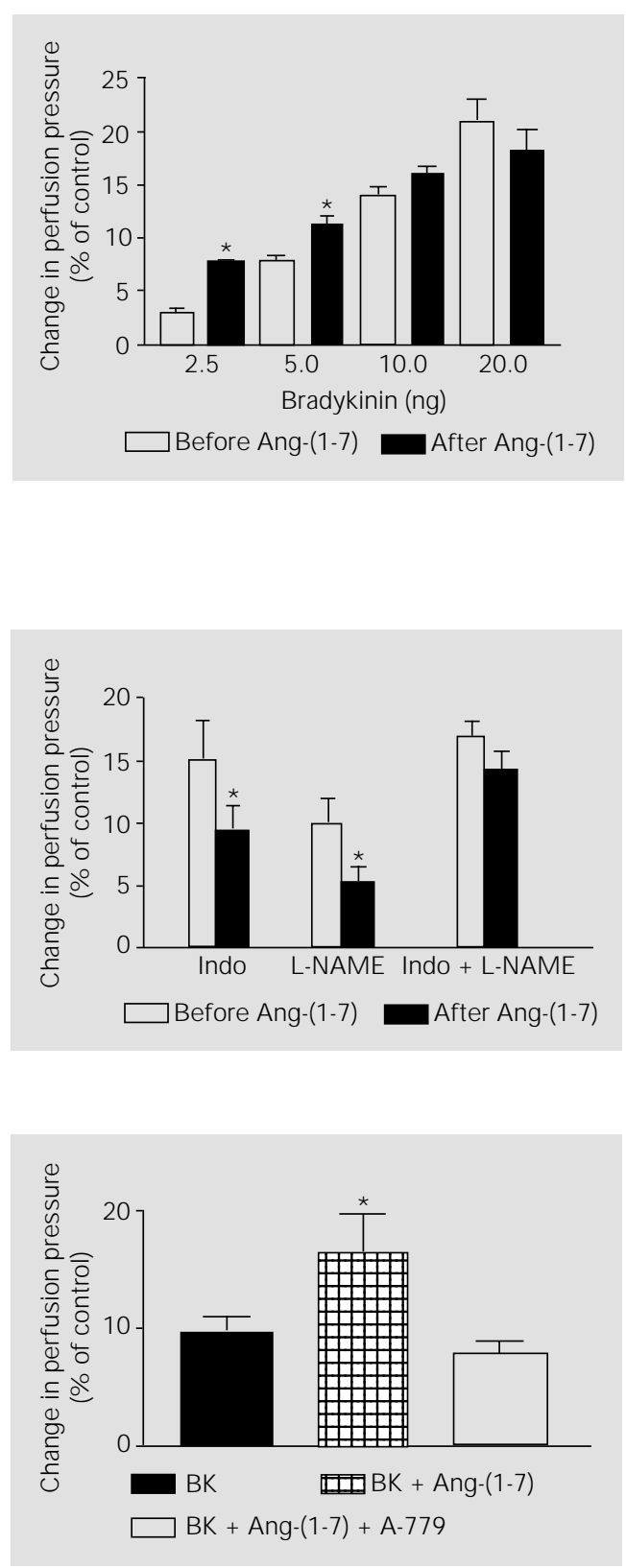

Figure 1 - Effect of bradykinin on isolated rat hearts perfused with Krebs-Ringer solution and KrebsRinger containing Ang-(1-7) (2.2 $n M)$. Values are reported as percent change in basal perfusion pressure. $* \mathrm{P}<0.05$ compared to bradykinin alone (ANOVA followed by the least significant test).

Figure 2 - Effect of indomethacin (Indo) and L-NAME on the bradykinin-potentiating activity of Ang-(1-7) in isolated rat hearts. Indomethacin $(5 \mathrm{mg} / \mathrm{kg}$, ip), L-NAME (30 mg/kg, ip) or indomethacin combined with $\mathrm{L}$ NAME at the same doses as indicated above were administered $1 \mathrm{~h}$ before animal sacrifice. The effect of bradykinin ( $2.5 \mathrm{ng}$ ) was determined before and after perfusion with Ang-(17) $(2.2 \mathrm{nM}) . * \mathrm{P}<0.05$ compared to values obtained before perfusion with Ang-(1-7) (Student ttest).

Figure 3 - Effect of A-779 on the bradykinin (BK)-potentiating activity of Ang-(1-7) in isolated rat hearts. The effect of BK ( $2.5 \mathrm{ng})$ was determined before and after perfusion with Ang-(1-7) (2.2 $\mathrm{nM}$ ) or Ang-(1-7) combined with A-779 (55 nM). *P<0.05 compared to BK alone (ANOVA followed by the Newman-Keuls test). 
duced vasodilation.

In a previous study we have shown that Ang-(1-7) at a concentration of $27 \mathrm{nM}$ decreases coronary flow (18). In contrast, at a concentration of $2.2 \mathrm{nM}$, as used in the present study, this heptapeptide had no detectable direct myotropic effect on coronary vessels. Although no direct effect of Ang-(1-7) on the isolated heart could be detected at this lower concentration, a clear potentiation of BK was observed. Thus, it appears that at concentrations close to the physiological range Ang-(1-7) would act as a kinin modulator on the coronary vessels. This observation is in accordance with a recent study showing a significant BK-potentiating activity of Ang-(1-7) in mesenteric vessels (13).

The mechanism of the interaction between Ang-(1-7) and BK is very complex $(12,15)$. Deddish and colleagues (12) have provided evidence for an interaction of Ang(1-7) with ACE that, independently of the enzymatic inhibition, would facilitate a crosstalk between $\mathrm{ACE}$ and the $\mathrm{BK} \mathrm{B}_{2}$ receptor leading to $\mathrm{BK}$ potentiation. On the other hand, in dog coronary artery the BKpotentiating activity of Ang-(1-7) was ascribed to ACE inhibition and NO release (14). In rats, we (11) and others (13) have blocked the BK-potentiating activity of Ang(1-7) with its selective antagonist, A-779, indicating that in this species a receptormediated mechanism is involved in BK potentiation. This appears to be true at least for the mesenteric and coronary circulation. One may argue that A-779 could interfere with the binding of Ang-(1-7) to ACE. However, we have recently shown that A-779 does not inhibit ACE and does not prevent Ang-(1-7) from inhibiting this enzyme (15).

As observed in the present study, pretreatment with indomethacin completely blocked BK potentiation in vivo (10) or in mesenteric vessels (13). These observations contrast with findings in dog coronary vessels (14). However, as observed in dogs (14) and in the rat mesenteric vascular bed (13), the BK-potentiating activity of Ang-(1-7) may be prevented by L-NAME treatment, suggesting a role for NO release in this action. The related observation that Ang-(1-7) did not change the vasodilator action of the NO donor sodium nitroprusside in vivo or in vitro $(10,13)$ indicates that the NO-related mechanism is dependent on the formation rather than on the action and/or inactivation of NO. Furthermore, these observations tend to exclude a role for interference with superoxide production in the BK-potentiating mechanism.

We have observed that the BK-potentiating activity of Ang-(1-7) could be demonstrated only when low doses of BK were used. This finding further suggests that BK potentiation by this heptapeptide is not related to interference with ACE activity or with other BK-inactivating enzymes. On the other hand, this observation suggests that Ang-(1-7) triggers a membrane and/or intracellular mechanism(s) that usually is fully activated only with higher doses of BK. In other words, in the presence of Ang-(1-7), lower doses of BK became able to fully activate this mechanism. A similar bellshaped BK-potentiating activity for Ang-(17) was recently described by Oliveira et al. (13) in rat mesenteric vessels. These findings are consistent with the related observation in cultured rabbit vascular smooth muscle cells that the release of arachidonic acid products by Ang-(1-7) follows a bell-shaped curve (19). Further experiments are needed to clarify these observations.

We have previously shown that Ang-(17) at $27 \mathrm{nM}$ concentration increased the incidence and duration of reperfusion arrhythmias in isolated rat hearts (18). Our current data showing a significant BK-potentiating activity of Ang-(1-7) at a lower concentration and the proposed anti-arrhythmic action of BK in this preparation (4) indicate the importance of evaluating the effect of low concentrations of Ang-(1-7) on reperfusion arrhythmias. 
In summary, we have shown that in isolated rat hearts Ang-(1-7) induced an increase in the vasodilator effect of $\mathrm{BK}$ by $\mathrm{NO}$ and prostaglandin release-related mechanisms and that this action may be receptor mediated.

\section{Acknowledgments}

The authors wish to thank Soraia S. Silveira for skillful technical assistance.

\section{References}

1. Dzau VJ (1988). Cardiac renin-angiotensin system: molecular and functional aspects. American J oumal of Medicine, 84: 22-27.

2. Phillips $M I$, Speakman EA \& Kimura B (1992). Levels of angiotensin and molecular biology of the tissue renin angiotensin systems. Regulatory Peptides, 43: 1-20.

3. Santos RAS \& Campagnole-Santos MJ (1994). Central and peripheral actions of angiotensin-(1-7). Brazilian J ournal of Medical and Biological Research, 27: 1033-1047.

4. Linz W, Wohlfart $P$, Schölkens BA, Malinski T \& Wiemer G (1999). Interactions among ACE, kinins and NO. Cardiovascular Research, 43: 549-561.

5. Gavras I (1992). Bradykinin-mediated effects of ACE inhibition. Kidney International, 42: 1020-1029.

6. Gohlke P, Linz W, Schölkens BA, Kuwer I, Bartenbach S, Schnell A \& Unger T (1994). Angiotensin-converting enzyme inhibition improves cardiac function: role of bradykinin. Hypertension, 23: 411-418.

7. Hecker M, Blaukat A, Bara AT, MüllerEsterl W \& Busse R (1997). ACE inhibition potentiation of bradykinin-induced venoconstriction. British J ournal of Pharmacology, 121: 1475-1481.

8. Campbell DJ , Kladis A \& Duncan A (1993). Nephrectomy, converting enzyme inhibition and angiotensin peptides. Hypertension, 22: 513-522.

9. Ferrario CM \& lyer SN (1998). Angio- tensin-(1-7): a bioactive fragment of reninangiotensin system. Regulatory Peptides, 78: 13-18.

10. Paula RD, Lima CV, Khosla MC \& Santos RAS (1995). Angiotensin-(1-7) potentiates the hypotensive effect of bradykinin in conscious rats. Hypertension, 26 (Part 6): 1154-1159.

11. Lima CV, Paula RD, Resende FL, Khosla MC \& Santos RAS (1997). Potentiation of the hypotensive effect of bradykinin by short-term infusion of angiotensin-(1-7) in normotensive and hypertensive rats. Hypertension, 30 (Part 2): 542-548.

12. Deddish PA, Marcic $B$, J ackman HL, Wang HZ, Skidgel AR \& Erdos EG (1998). NDomain-specific substrate and c-domain inhibition of angiotensin-converting enzyme: angiotensin-(1-7) and keto-ACE. Hypertension, 31: 912-917.

13. Oliveira MA, Fortes ZB, Santos RAS, Khosla MC \& Carvalho MHC (1999). Synergistic effect of angiotensin-(1-7) on bradykinin arteriolar dilatation in vivo. Peptides, 20: 1195-1201.

14. Li P, Chappell MC, Ferrario CM \& Brosnihan KB (1997). Angiotensin-(1-7) augments bradykinin-induced vasodilation by competing with ACE and releasing nitric oxide. Hypertension, 29 (Part 2): 394400.

15. Paula RD, Lima CV, Britto RR, Campagnole-Santos MJ, Khosla MC \& Santos RAS (1999). Potentiation of the hypotensive effect of bradykinin by angiotensin (1-7)-related peptides. Peptides, 20: 493-500.

16. Chappell MC, Piro NT, Skykes A \& Ferrario CM (1998). Conversion of angiotensin-(17) by angiotensin converting enzyme. Hypertension, 31 (Part 2): 362-367.

17. Santos RAS, Campagnole-Santos MJ, Baracho NCV, Fontes MAP, Silva LCS Neves LAA, Oliveira DR, Caligiome SM, Rodrigues ARV, Gropen J r C, Carvalho WS, Silva ACS \& Khosla MC (1994). Characterization of a new angiotensin antagonist selective for angiotensin-(1-7): Evidence that the actions of angiotensin-(17) are mediated by specific angiotensin receptors. Brain Research Bulletin, 35: 293-299.

18. Neves LAA, Almeida AP, Khosla MC, Campagnole-Santos MJ \& Santos RAS (1997). Effect of angiotensin-(1-7) on reperfusion arrhythmias in isolated rat hearts. Brazilian J ournal of Medical and Biological Research, 30: 801-809.

19. Muthalif $M M$, Benter IF, Uddin $M R$, Harper J L \& Malik KU (1998). Signal transduction mechanisms involved in angiotensin-(1-7)-stimulated arachidonic acid release and prostanoid synthesis in rabbit aortic smooth muscle cells. J ournal of Pharmacology and Experimental Therapeutics, 284: 388-398. 